\title{
Influencia de la idea de raza en la práctica médica. Una reflexión a partir de un estudio sobre el diagnóstico y tratamiento de la infección de la vía aérea superior en niños en los Estados Unidos
}

\author{
How the concept of race influences medical practice.
} A reflection based on a study about the diagnosis and treatment of upper respiratory tract infections in American children

La evidencia científica demuestra que existen distinciones importantes, persistentes y generalizadas en el estado y el cuidado de la salud de los niños de acuerdo la diferencia en el color de su piel, identificada en los Estados Unidos como una diferencia racial.

Diferentes trabajos muestran mayor tasa de mortalidad infantil, mayor incidencia de muertes en accidentes, en leucemia linfocítica aguda, cardiopatías congénitas, síndrome de Down, etc. en la población negra. ${ }^{3}$

También se describe en la población afroamericana menor incidencia de lactancia materna y menor acceso al sistema de salud.

La incidencia de embarazo adolescente en las jóvenes y de violencia en los varones son también mayores en la población afroamericana.

Por todos estos y muchos otros indicadores, el problema de las diferencias en salud establecidas a partir del color de la piel de los pacientes en los Estados Unidos no puede ser soslayada.

Un trabajo reciente, publicado en Pediatrics ${ }^{1}$ investiga si hay diferencias en cómo un mismo médico diagnostica y trata una infección de la vía aérea superior de acuerdo a las características "raciales" del paciente.

Los resultados indican que sí las hay, básicamente que en los niños negros se hace con menos frecuencia diagnósticos que justifiquen un tratamiento antibiótico (especialmente otitis media aguda y faringitis estreptocócica), y que si éste es indicado, se decide por antibióticos de menor espectro que cuando la indicación se hace a niños "blancos".

Los autores sugieren que estudiar y comprender estas diferencias en las indicaciones del tratamiento de infecciones frecuentes puede ayudar a disminuir el uso inadecuado de antibióticos en una era de resistencia creciente y escasa producción por parte de la industria de nuevos antibióticos.

En primer lugar, haré alguna especulación sobre las posibles causas de que el mismo médico haga diagnósticos e indicaciones terapéuticas diferentes de acuerdo al color de la piel del paciente, luego, un comentario sobre el uso del término "raza" en la bibliografía anglosajona, especialmente estadounidense y por último una reflexión sobre la idea de raza en nuestro país.

Los autores no dan su opinión respecto a la causa de estas diferencias significativas, y lo dejan abierto a futuros estudios, pero aclaran que no hay justificación "biológica" ya que los niños negros tienen igual o mayor cantidad de otitis media aguda y de otras infecciones que los blancos, sin embargo en este estudio reciben un $25 \%$ menos de indicación de antibióticos. Más aun, un trabajo reciente muestra una incidencia desproporcionadamente mayor en niños negros de infecciones por Staphylococcus aureus meticilino resistente. ${ }^{2}$

Los autores especulan que la mayor frecuencia en la indicación de antibióticos en la población blanca implica más un sobretratamiento de ésta que un subtratamiento de la población de niños negros.

Varios trabajos ${ }^{3,4}$ demuestran que las indicaciones de los médicos son influenciadas por las expectativas parentales, y que es más probable que un niño sea medicado con antibióticos y que se llegue a un diagnóstico que los justifique cuando los padres lo solicitan o lo esperan. Estos trabajos también demuestran que los padres de niños negros son menos demandantes que los de niños blancos lo que puede, al menos en parte, explicar los resultados de este trabajo.

También surge de algunas investigaciones ${ }^{4}$ que la creencia por parte de los médicos que la adherencia al tratamiento será menor en la población negra, hace que los antibióticos sean menos indicados que en la población blanca.

El hecho de que esta diferencia en el diagnóstico de enfermedades infecciosas frecuentes como la otitis media aguda y la faringitis, no se dé en el tratamiento de la infección urinaria cuyo diagnóstico responde a datos más objetivos o en la neumonía cuya 
falta de diagnóstico tendrá consecuencias serias, muestra la subjetividad implícita en el manejo de infecciones del tracto respiratorio superior.

Una variable que no es tenida en cuenta en este trabajo es el origen étnico o "racial" de los investigadores, ya que otros trabajos demuestran diferentes actitudes acordes a la concordancia "racial" o no del médico con el paciente. ${ }^{4}$

Paradójicamente, este estudio parece demostrar que los niños negros, en general en peor situación socioeconómica que los blancos, reciben una mejor indicación de antibióticos que la población blanca que probablemente es tratada con antibióticos en muchos casos por infecciones virales especialmente rinosinusitis, con el consiguiente efecto en la resistencia bacteriana del paciente y su entorno.

Un estudio reciente ${ }^{5}$ señala que de 50 millones de prescripciones de antibióticos por cuadros de la vía aérea superior en niños en los Estados Unidos, 10 millones son injustificadas por la etiología viral de las infecciones. Si bien en parte esto se debe a la dificultad en ocasiones de diferenciar un cuadro viral de uno bacteriano, también juegan factores como los que surgen de este trabajo, como las presiones o las expectativas de los padres.

En una etapa del desarrollo científico donde se sabe que no hay diferencias en el genoma entre individuos de diferente color, mayores a los que se encuentran entre individuos del mismo, parece útil acercarse al concepto de raza desde otro punto de vista que el biológico.

Si bien hay autores que todavía defienden que la raza tiene relación con la naturaleza humana, la mayor parte lo niega y lo ven como una construcción social, no definible en términos biológicos sino producto de procesos sociales.

El uso habitual del criterio de "raza" en la literatura médica norteamericana puede relacionarse con los criterios estrictos con que históricamente se clasificaba a una persona como negra en los Estados Unidos.

A diferencia de Latinoamérica donde se llamaba "negro" a una persona de ascendencia africana muy evidente, Estados Unidos se manejaba con la norma de la "única gota", en que las personas con una sola "gota" de "sangre" africana en las venas era clasificada como negra. ${ }^{6}$

Este contraste, que tiene que ver con las distintas formas de colonización por parte de británicos e ibéricos, demuestra que las identidades raciales son construcciones surgidas a lo largo del tiempo, configuradas por fuerzas sociales, que han permitido legitimar las jerarquías sociales en tanto presentan a las ideas de superioridad-inferioridad implicadas en toda relación de dominación como diferencias de naturaleza, ocultando de este modo su carácter histórico. $^{7}$

Las teorías que adscribían al concepto de raza diferencias no solo en el aspecto físico si no en la inteligencia no se sostienen a la luz del conocimiento actual, sin embargo el concepto de "raza" sigue teniendo una enorme importancia social.

La evidencia actual sostiene que la variación genética existente en el ser humano no puede explicarse en términos de raza. El concepto de raza es una idea sin relevancia biológica significativa (al margen de ciertas predisposiciones a enfermedades) pero de enorme importancia social.

En nuestro país, por el concepto de "crisol de razas" inicialmente y en nombre de lo políticamente correcto en la actualidad, se ha ocultado el concepto de raza, pero los prejuicios inherentes al color de la piel, al origen indígena o mestizo o a la cultura de determinados grupos siguen presentes. Esto conlleva a una clasificación de las diferencias sociales y culturales en términos raciales $y$, de ese modo, a un establecimiento de cadenas de actitudes y conductas, construidas a partir del origen étnico, nacional o del color de la piel de los individuos.

Creo interesante reflexionar sobre los modos en que estos prejuicios instalados en la sociedad se introyectan en nuestro sistema de salud, conduciendo en determinados casos a diferentes acercamientos, diagnósticos y terapéuticas hacia los pacientes por parte de los médicos, basados en un complejo sistema de clasificación social en el que se intersectan prejuicios raciales, nacionales y de clase, que establecen jerarquías entre los pacientes. Esta jerarquización puede darse, incluso, en la práctica específica de un mismo médico que atiende de distinto modo a la población que acude al hospital público respecto de quienes concurren al consultorio privado.

En este sentido, la idea actualmente aceptada de que las "razas" son construcciones sociales, no descarta que la noción de "raza" esté profundamente arraigada y que afecte en forma muy importante el comportamiento de la gente y sus posibilidades.

Dr. Carlos Wahren

Departamento de Pediatría Hospital Italiano de Buenos Aires

http:/ /dx.doi.org/10.5546/aap.2014.204 


\section{BIBLIOGRAFÍA}

1. Gerber JS, Prasad PA, Localio AR, Fiks AG, et al. Racial Differences in Antibiotic Prescribing by Primary Care Pediatricians. Pediatrics 2013;131(4):677-84.

2. Iwamoto $\mathrm{M}, \mathrm{Mu} \mathrm{Y}$, Lynfield R, Bulens $\mathrm{SN}$, et al. Trends in invasive methicillin-resistant Staphylococcus aureus infections. Pediatrics 2013;132(4):e817-24.

3. Flores G. Racial and Ethnic Disparities in the health and health care of children. Pediatrics 2010;125(4):e979-1020.

4. Mangione-Smith R, Elliott MN, Stivers T, McDonald L, et al. Racial/Ethnic variation in parent expectations for antibiotics: implications for public health campaigns. Pediatrics 2004;113(5):e385-94.

5. Hersh AL, Jackson MA, Hicks LA. Principles of judicious antibiotic prescribing for upper tract respiratory tract infections in pediatrics. Pediatrics 2013;132(6):1146-54.

6. Wade P. Human Nature and Race. Anthropol Theory 2004;4:157-72.

7. Quijano A. Raza, etnia y nación en Mariátegui: cuestiones abiertas. En: Roland Forgues (ed). José Carlos Mariátegui y Europa: el otro aspecto del descubrimiento. Lima: Amauta; 1992:167-87.

La reciente ley que transcribimos significa un anhelado y merecido homenaje al $\mathrm{Dr}$. Carlos Gianantonio nuestro siempre presente maestro. Si bien su figura trascendió mucho más allá de sus investigaciones en el Síndrome Urémico Hemolítico, este reconocimiento que fija la fecha de su nacimiento como día relacionado a esa enfermedad, nos llena de alegría. Seguramente, él no habría estado de acuerdo con esta distinción ya que era sumamente humilde y contrario a cualquier tipo de homenaje, no obstante bienvenida sea para quien sin duda es el padre de la pediatría en la Argentina.

José M. Ceriani Cernadas

\section{CONGRESO DE LA NACIÓN}

Ley 26926

Día Nacional de la Lucha contra el Síndrome Urémico Hemolítico en homenaje al Dr. Carlos Arturo Gianantonio.

Sancionada: Noviembre 27 de 2013.

Promulgada de Hecho: Diciembre 19 de 2013.

ARTICULO $1^{\circ}$ - Institúyese en el territorio de la Nación el día 19 de agosto de cada año como Día Nacional de la Lucha contra el Síndrome Urémico Hemolítico en homenaje al Dr. Carlos Arturo Gianantonio, precursor en la lucha contra esta enfermedad.

ARTICULO $2^{\circ}-$ El Poder Ejecutivo, a través de los organismos pertinentes y con la participación de organizaciones no gubernamentales que lleven adelante programas relacionados con la materia objeto de la presente, impulsará durante la semana del 19 de agosto de cada año una campaña intensiva de concientización, a fin de informar a la sociedad los métodos para prevenir y detectar el síndrome urémico hemolítico.

ARTICULO $3^{\circ}-$ El Ministerio de Educación de la Nación, en acuerdo con el Consejo Federal de Educación, arbitrará los medios necesarios para su inclusión en el calendario escolar y en la currícula.

ARTICULO $4^{\circ}$ - Comuníquese al Poder Ejecutivo nacional.

También disponible en:

http://www.infoleg.gob.ar/infolegInternet/anexos/220000-224999/224583/norma.htm 